UCRL-JC-131853

Preprint

\title{
A Diode-Pumped Channel Waveguide Laser Fabricated in Nd: Phosphate Glass
}

\author{
F. D. Patel, E. C. Honea, D. Krol, S. A. Payne, J. S. Hayden
}

This paper was prepared for submittal to

Fourteenth Topical Meeting on Advanced Solid-State Lasers

Boston, MA

Jan. 31- Feb.3, 1999

January 29, 1999

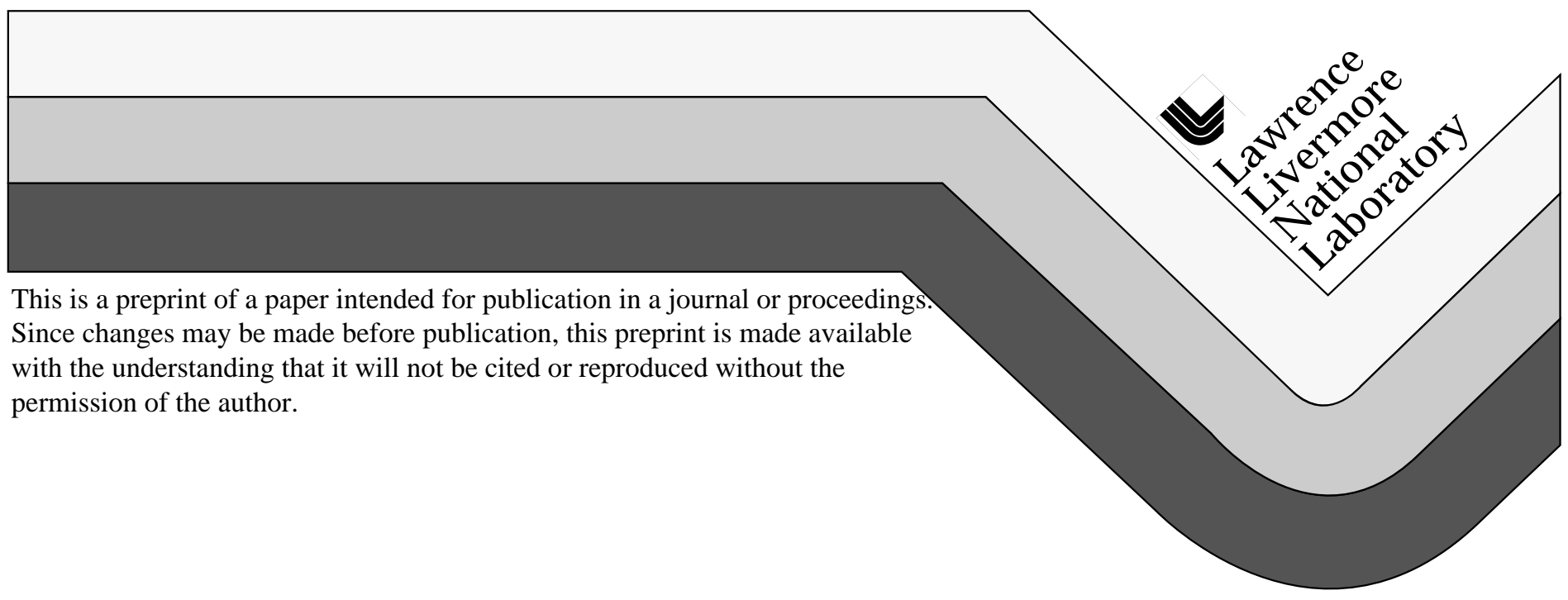




\section{DISCLAIMER}

This document was prepared as an account of work sponsored by an agency of the United States Government. Neither the United States Government nor the University of California nor any of their employees, makes any warranty, express or implied, or assumes any legal liability or responsibility for the accuracy, completeness, or usefulness of any information, apparatus, product, or process disclosed, or represents that its use would not infringe privately owned rights. Reference herein to any specific commercial product, process, or service by trade name, trademark, manufacturer, or otherwise, does not necessarily constitute or imply its endorsement, recommendation, or favoring by the United States Government or the University of California. The views and opinions of authors expressed herein do not necessarily state or reflect those of the United States Government or the University of California, and shall not be used for advertising or product endorsement purposes. 
UCRL-JC-131853

\title{
A diode-pumped channel waveguide laser fabricated in Nd:phosphate glass
}

\author{
Falgun D. Patel, Eric C. Honea, Denise Krol, Stephen A. Payne \\ Lawrence Livermore National Laboratory, P O Box 808, L-482, Livermore CA 94551 \\ Tel: (925) 424-5986, Fax: (925) 423-6195 \\ falgun@LLNL.GOV \\ Joseph S. Hayden \\ Schott Glass Technologies, Inc. \\ 400 York Ave, Duryea, PA 18642; (570) 457-7485
}

\begin{abstract}
We report on the laser performance of a Nd:phosphate glass (Nd:IOG-1) channel waveguide laser fabricated by electric field assisted $\mathrm{Ag}^{+}$diffusion. Lasing was achieved in two different size channels, $29 \times 9 \mu \mathrm{m}^{2}$ and $50 \times 9 \mu \mathrm{m}^{2}$, on a sample of length $8 \mathrm{~mm}$. Slope efficiencies of $\sim 15 \%$ with respect to incident pump power were measured. Losses in the 29 um wide channel were measured to be in the range $0.2-1.1$ $\mathrm{dB} / \mathrm{cm}$ and in the $50 \mu \mathrm{m}$ channel, $0.2-0.4 \mathrm{~dB} / \mathrm{cm}$. The laser spectrum, centered about the emission peak of $1053 \mathrm{~nm}$, was multimode and randomly polarized.

OCIS codes: $140.3480,140.3530,140.3580,140.5680$
\end{abstract}

Solid-state waveguide lasers [1-5] offer several attractive features that may make high efficiency and effective thermal management possible. The waveguide region is typically several microns thick, leading to high intensities of the pump light over distances much longer than the Rayleigh range. Good overlap is maintained between the pump and signal modes over the entire guiding region, leading to efficient operation with high slope efficiency. The effects of heating are of less significance than in typical solid-state lasers because mode confinement is maintained by an index of refraction difference, usually much larger than that induced by $\mathrm{dn} / \mathrm{dT}$ or stress-optic effects. The high NA of the waveguide is also suitable for diode pumping.

We report on laser performance in a Nd:phosphate glass (Nd:IOG-1). The fabrication process for the waveguides used for the laser experiments has been reported previously [6], but is summarized here for convenience. A thin film of $\mathrm{Ag}$ was evaporated on a $1 \mathrm{~mm}$ x $50.8 \mathrm{~mm}$ square Nd:phosphate glass substrate. Another metal film (Ag or $\mathrm{Al}$ ) was evaporated on the opposite side. Photolithography was used to define $\mathrm{Ag}$ lines, varying in widths from $2 \mu \mathrm{m}$ to $400 \mu \mathrm{m}$. The thin lines $(2-8 \mu \mathrm{m})$ did not adhere well to the substrate and were removed during the etching process. Once the lines of Ag were formed on the substrate, an Al cap layer was evaporated on top to ensure good electrical contact during the next step. An electric field was then applied across the sample, which was placed in a furnace. The diffusion time and temperature were 30 minutes and $300^{\circ} \mathrm{C}$, respectively. The remaining metal films were removed by placing the sample in a dilute solution of nitric acid (69\% assay). Planar waveguides, fabricated under the same conditions, were characterized by the prism coupling method and electron microprobe analysis [7]. The channel waveguide samples were then cut and laser grade polished to various lengths. The waveguide ends were parallel to within 30" as judged from interferograms.

The laser resonator was set up in a Fabry-Perot configuration. Index matching oil $(\mathrm{n}=1.512)$ was used to butt-couple the mirrors to the substrate $\left(\mathrm{n}_{\mathrm{d}}=1.52401, \mathrm{~V}_{\mathrm{d}}=67.27\right)$. The surface tension of the oil held the mirrors in contact with the waveguide. Aspheres, $\mathrm{NA}=0.5, \mathrm{f}=8 \mathrm{~mm}$, were used to focus light into the waveguide and collimate the output beam. An SDL 8630 diode laser served as the 
pump source, with a pump wavelength of $806.5 \mathrm{~nm}$. At this wavelength, the pump absorption coefficient is $3.3 \mathrm{~cm}^{-1}$ leading to an estimated $93 \%$ pump absorption efficiency. Fig. 1 shows the slope efficiency for a $50 \times 9 \mathrm{~m}^{2}$ channel with a $62 \%$ output coupler reflectivity. The slope efficiencies obtained are $14.6 \%$ and $14.1 \%$ for TE and TM polarized pump beams, respectively; the difference between the two being minor.

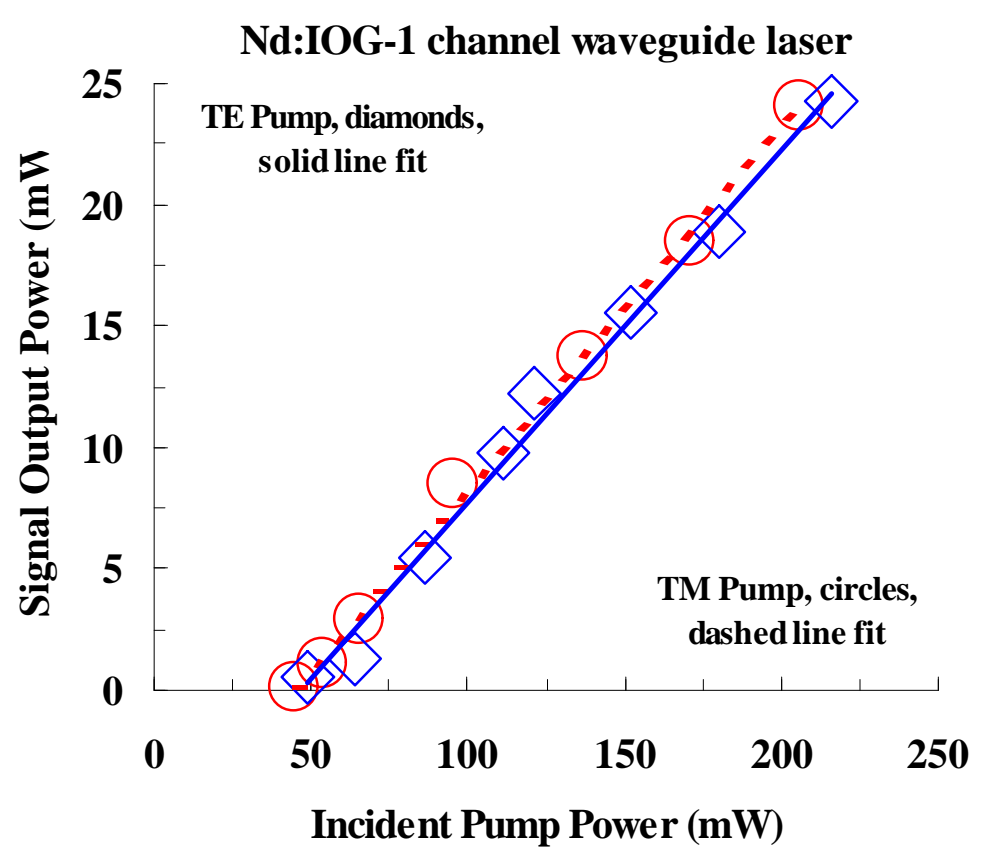

Fig. 1. Slope efficiencies of $50 \times 9 \mu \mathrm{m}^{2}$ channel waveguide laser.

Knowledge of the amount of loss in the laser cavity is essential in understanding the performance of the laser. One standard method of measuring loss in a four level laser is the Findlay-Clay [8] analysis, where the threshold power is measured as a function of varying output coupling. Three output coupler reflectivities of $97 \%, 82 \%$, and $62 \%$ were used in the experiment. The losses measured for the $50 \mu \mathrm{m}$ channel with this analysis are $0.28-0.39 \mathrm{~dB} / \mathrm{cm}(\operatorname{Loss}[\mathrm{dB} / \mathrm{cm}]=\mathrm{Loss} / 4.34[1 / \mathrm{cm}])$. The measured losses in the 29 um channel were much higher, from $0.58-1.12 \mathrm{~dB} / \mathrm{cm}$. No lasing was observed with lower reflectivity mirrors.

Another method to measure loss was reported by Caird, et. al. [9], where inverse slope efficiencies are plotted as a function of inverse output coupling (Fig. 2). Starting from

$$
\eta_{\mathrm{s}}=\eta_{0} \frac{T}{T+\delta}
$$

one can invert the above equation to obtain

$$
\frac{1}{\eta_{s}}=\left(\frac{\delta}{\eta_{0}}\right) \frac{1}{T}+\frac{1}{\eta_{0}}
$$


where $\eta_{\mathrm{s}}$ is the slope efficiency, $\delta$ is the round trip loss $(2 \alpha \mathrm{l})$, T is the output coupling, and $\eta_{0}$ represents the intrinsic slope efficiency. $\eta_{0}$ is inclusive of efficiencies for pump delivery, pump absorption, the overlap of the pump and signal modes, and the quantum efficiency of the lasant ion. The round trip loss, $\delta$, neglects losses due to scattering off the resonator mirrors. This assumption is valid since both the HR and the OC are butt coupled directly to the waveguide, thus mitigating any diffraction losses. With this analysis, general agreement is reached with the Findlay-Clay analysis for the $50 \mu \mathrm{m}$ channel, with losses of $0.21-0.26 \mathrm{~dB} / \mathrm{cm}$. For the $29 \mu \mathrm{m}$ channel losses were measured to be $0.21-0.23 \mathrm{~dB} / \mathrm{cm}$, comparable to those of the $50 \mu \mathrm{m}$ channel, as expected.

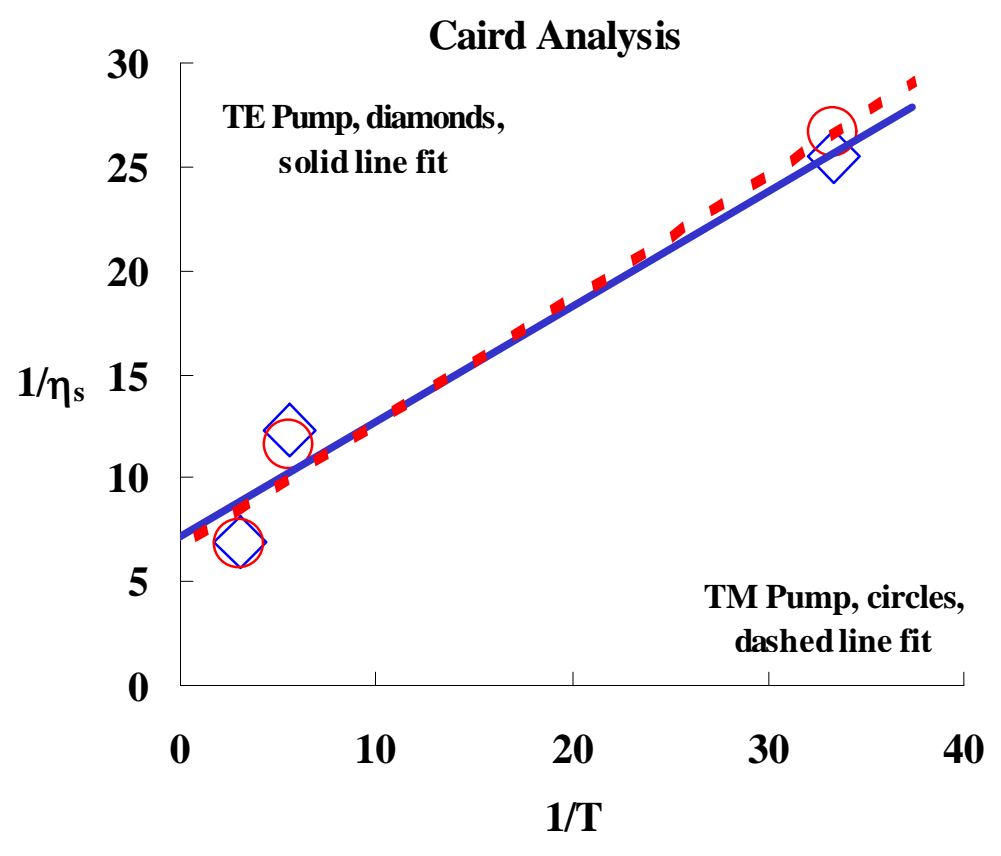

Fig. 2. Caird analysis for the $50 \times 9 \mathrm{~m}^{2}$ channel waveguide laser.

The intercept, $\eta_{0}$, obtained from the Caird analysis allows the determination of the pump delivery efficiency into the waveguide.

$$
\eta_{\text {pump delivery }}=\left(\frac{\eta_{0}}{\eta_{\text {abs }} \eta_{\text {overlap }}}\right) \frac{\lambda_{\text {laser }}}{\lambda_{\text {pump }}}
$$

Since the waveguide is multimode, the assumption that the overlap efficiency is unity is valid. The pump radiation should excite several laser modes, thus completely overlapping with the signal radiation. The absorbed pump efficiency is 0.93 as stated previously. The laser and pump wavelengths are 1053 nm and $806.5 \mathrm{~nm}$, respectively. From Eq. 3, an average pump delivery efficiency of $\sim 19 \%$ for both channels is obtained.

The laser operated at a single wavelength, as resolved by an optical spectrum analyzer $(\Delta \lambda=0.5$ $\mathrm{nm}$ ) at threshold output power as shown in Fig. 3. As the input pump power was increased, other laser lines began to oscillate, with each line having a FWHM $\sim 0.5-1.0 \mathrm{~nm}$. The signal was randomly polarized for both input pump (TE and TM) polarizations. The multiple lines and random polarization of the signal light were expected since the waveguide can support many transverse modes at both 
polarizations. Also, the inhomogeneously broadened laser transitions of Nd:glass allows more than one line to oscillate.

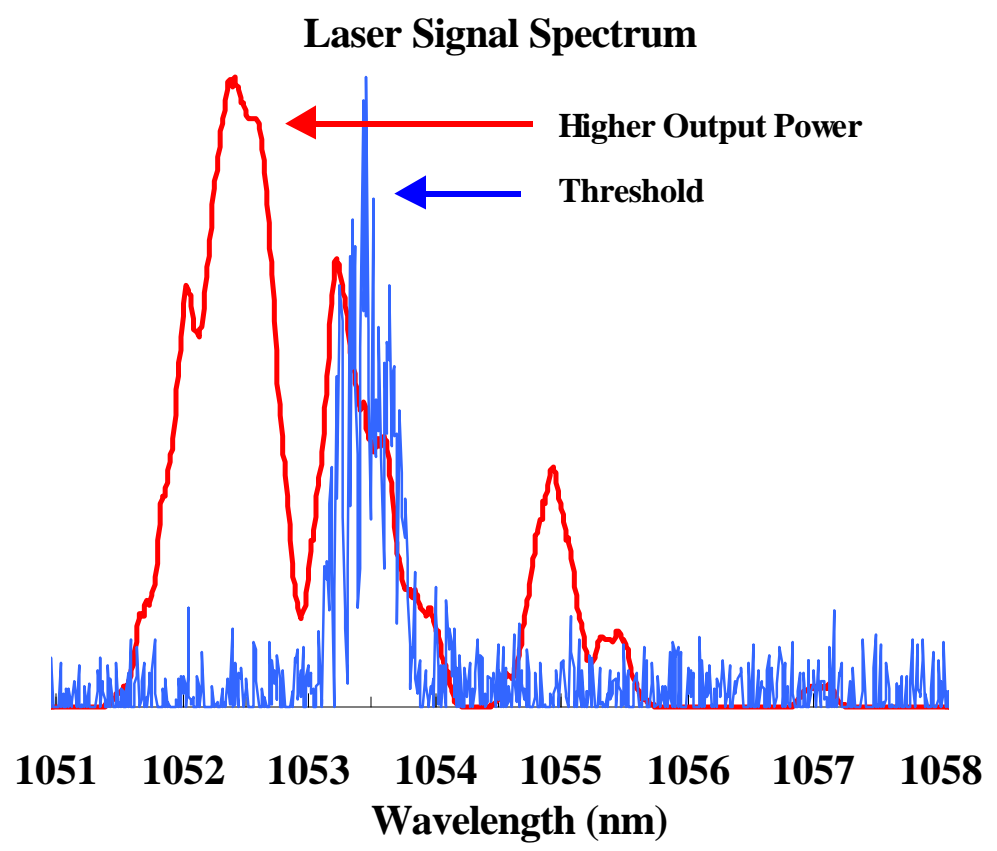

Fig. 3. Laser spectrum of $50 \times 9 \mu \mathrm{m}^{2}$ channel waveguide laser.

In summary, Ag diffusion is an attractive choice for waveguide fabrication because its corresponding monovalent ion easily displaces, under proper conditions, a $\mathrm{Na}^{+}$present in the glass. The $\mathrm{Ag}^{+}$for $\mathrm{Na}^{+}$exchange results in a relatively large increase in the local index of refraction, thus providing the waveguide with a high NA suitable for coupling of diode pump radiation. However, a possible disadvantage of using Ag is that during fabrication the ionic Ag may be reduced to colloid form through a redox interaction with refining agents or antisolarants present in the glass matrix. The presence of $\mathrm{Ag}$ colloids in the guiding region leads to increased losses from scatter and absorption. The IOG-1 glass from Schott is designed to eliminate Ag colloids, which should therefore lead to low loss waveguides. We have measured losses as low as $0.2 \mathrm{~dB} / \mathrm{cm}$ at the laser wavelength. The losses reported for Nd:IOG1 are very good for a diffused channel waveguide laser since sample lengths required for efficient operation are very small $(\sim 1 \mathrm{~cm})$. Improvement in the processing should further decrease the losses. The results are promising for waveguide lasers in other rare-earth doped IOG-1 glasses, thus allowing the possibility in the near future for novel compact solid-state laser sources.

\section{Acknowledgements}

We would like to thank Ralph Page and Ray Beach for helpful discussions. We also thank Cathy Reinhardt for the photolithography processing. This work was performed under the auspices of the U.S. Department of Energy, Office of Basic Energy Sciences, Division of Materials Sciences, by Lawrence Livermore National Laboratory under Contract No. W-7405-ENG-48. 


\section{References}

1. T. Feuchter, et. al., "Erbium-Doped Ion-Exchanged Waveguide Lasers in BK-7 Glass," IEEE Photon. Tech. Lett., $\underline{4}$, No. 6, pp. 542-544 (1992).

2. D.C. Hanna, et. al., "Quasi-three level 1.03 um laser operation of a planar ion-implanted Yb:YAG

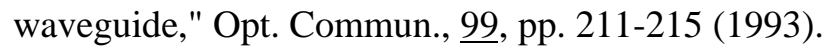

3. D.P. Shepherd, et. al., "1.9 um operation of a Tm:lead germanate glass waveguide laser," Opt Lett., $\underline{19}$, No. 13 pp. 954-956 (1994).

4. K. Malone, N. Sanford, J. Hayden, "Integrated optic laser emitting at 906, 1057, and 1358 nm," Electon. Lett., 8, p. 691 (1993).

5. C.T.A. Brown, et. al., "Thermally bonded planar waveguide lasers," Appl. Phys. Lett., $\underline{71}$, No. 9, pp. 11391141 (1997).

6. F.D. Patel, et. al., "Waveguide fabrication in Nd3+ and Yb3+ doped phosphate glasses," OSA TOPS Vol. 19, Advanced Solid State Lasers, W. R. Bosenberg and M. M. Fejer (eds.), pp. $446-9$ (1998).

7. F.D. Patel, et. al., "Nd3+ and Yb3+ doped phosphate glass waveguides fabricated using electric field assisted Ag+ diffusion," Proceedings of the XVIII International Congress on Glass, July 1998, Paper ICG096-C07003.

8. D. Findlay and R.A. Clay, "The measurement of internal losses in 4-level lasers," Phys. Lett., 20, pp. 277-8, (1966).

9. J.A. Caird, et. al., "Quantum Electronic Properties of the Na3Ga2Li3F12:Cr3+ Laser," IEEE J. Quantum Electron., 24, No. 6, pp. 1077-1099 (1988). 